\title{
Analysis of Urbanization Trends in the Greater Colombo Area from 1956 to 1994 Using Air Photos
}

\author{
Malik Majeed
}

\section{INTRODUCTION}

\subsection{Background}

Ụrban areas in Sri Lanka are declared politically on the basis of administrative units. However, there has been no such declaration in more than 20 years although this has been a period of considerable urban development. Further, there is no census data available on urbanization even on the basis of administrative units. As recent data, analysts have only the sample demographic survey in 1994 , to go by.

Under these circumstances, other sources of data which help define and delineate urban areas assume greater importance. This paper analyses the trends of urbanization in the Greater Colombo area by the use of airphotos of $1956(1: 50,000) 1981(1: 40,000)$ and $1994(1: 20,000)$

The trend analysis contributed to identifying future urban growth scenarios (up to the year 2010), for the Colombo Urban Transport Study.

\subsection{Advantages of Air -Photos}

Air-photos (Aps) which are now widely used as a data source in many fields have the following advantages over field surveys.

i) As boundaries of urban areas do not correspond to administrative boundaries, a more accurate delineation of urban areas is possible with APs even with scales as small as $1: 50,000$.

ii) Aps provide an instant snapshot over a wide area so that with periodical coverage over the same area, they facilitate rapid assessment of trends.

iii) Spatial patterns of urban growth such as the urban core, clusters, ribbon development, and sprawl can be very clearly visualized by the use of Aps.

iv) They are arguably cheaper than field surveys, especially when the cost of AP coverage could be apportioned over a number of projects that use the data.

\subsection{Definition of Urban Area}

Considering the purpose of the study and the source of data, urban areas were defined as follows.

i) A continuos block of built-up land around Colombo city which forms the urban core.

ii) All enclaves of non built-up land within this core.

iii) Apart from built-up areas, parks, playgrounds and other open amenity spaces were also defined as urban.

iv) Outside the core, a minimum area criterion, determined by air-photo scale and cartographic constraints had to be used to delineate urban areas so that in the case of the smallest scale Aps $(1: 50,000)$ the minimum delineation unit was 1 ha (ie. $2 \mathrm{~mm} \times 2 \mathrm{~mm}$ ).

Although it was possible to have smaller extents of area in the case of the larger scale Aps (ie. 1: 40,000 and 1:20,000), the above was adopted as the minimum delineation unit throughout for reasons of consistency. 
(v) At the urban fringe where built - up areas thinly spread, an aggregation criterion was used which related the length of building with perpendicular distances separating them. Any area that was equal to or greater than the minimum delineation unit on the basis of such aggregation of built -up area, was defined us urban.

\section{ANALYSIS OF URBANISATION TRENDS}

The analysis is based primarily on the map of urbanization trend (map 1) produced by the interpretation of Aps. It deals first with the urban situation in

1956 followed by the urbanization in the periods 1956-1981 and 1981-1994.

\subsection{Urban Area in 1956}

The urban area in 1956 included Colombo city, Nugegoda, Dehiwela/ Mt Lavinia municipal council area excluding Attidiya and parts of Moratuwa urban council area. In addition there were mainly, the satellite towns of Negombo, Gampaha, Ragama, Panadura and Kalutara (map 1).

The urban area added upto 7,200 ha in 1956 and comprised $5 \%$ of the study area which covered a major part of the Western Province. The urban core (ie: block of continuous built- up area) made up $75 \%$ of the urban area reflecting the urban concentration around Colombo (table 1)

\begin{tabular}{|l|l|c|c|c|c|c|}
\hline $\begin{array}{l}\text { Urban Area } \\
\text { (ha.) }\end{array}$ & 1956 & $\%$ & 1981 & $\%$ & 1994 & $\%$ \\
\hline Core Area & 5288 & 73.45 & 13744 & 64.25 & 20293 & 56.48 \\
\hline Peripheral Areas & 1911 & 26.55 & 7648 & 35.75 & 15635 & 43.52 \\
\hline \multicolumn{1}{|c|}{ TOTAL } & $\mathbf{7 1 9 9}$ & $\mathbf{1 0 0 . 0 0}$ & $\mathbf{2 1 3 9 2}$ & $\mathbf{1 0 0 . 0 0}$ & $\mathbf{3 5 9 2 8}$ & $\mathbf{1 0 0 . 0 0}$ \\
\hline
\end{tabular}

Table 1 Extent of Urban in the Study Area (Ha)

2.2 Urbanization this period, the urban core area expanded upto Kerawalapitiya (2.5 $\mathrm{km}$ north of Wattala) in the north. Kotikawatte in the east, Navinna in the south- east and Egoda Uyana $(2.5 \mathrm{~km}$ north of Panadura) in the south (map 1). The core area had grown by $160 \%$. However the percentage of the core area, in relation to the total urban area had declined to $64 \%$ reflecting a greater increase in the peripheral areas ( table 1).

This increase was the result of ribbon development along Colombo-Katunayake road from Welisara to Ja- Ela and again from Seeduwa to Negombo and along Galle road from Kudawaskaduwa to Katukurunda. There was growth around Kalutara town as well. In areas ear and south -east of Colombo, there was considerable ribbon development along secondary roads too (map 1).

In extent, the total urban area had grown to 21,400 ha, covering $15 \%$ of the study area. This represented a $200 \%$ increase over the 25 years, or an annual increase of $8 \%$.

By overlaying the boundaries of Assistant Government Agent (AGA) divisions on the map of urbanization, it was possible to analyze trends in terms of administrative units. The AGA divisions with the higher percentage of the total urban growth during this period was Kesbewa, Negombo, Panadura, Maharagama and Kolonnawa which together had $43 \%$ of the total urban growth. Moratuwa, Nugegoda and Kaduwela followed with $20 \%$ of the total urban growth (table 2). 
Built-Environment-Sri Lanka; Volume 1, Issue 1; December 1998 MAP OF URBANIZATION TREND IN STUDY AREA

COLOMBO URBAN TRANSPORT STUDY-1995

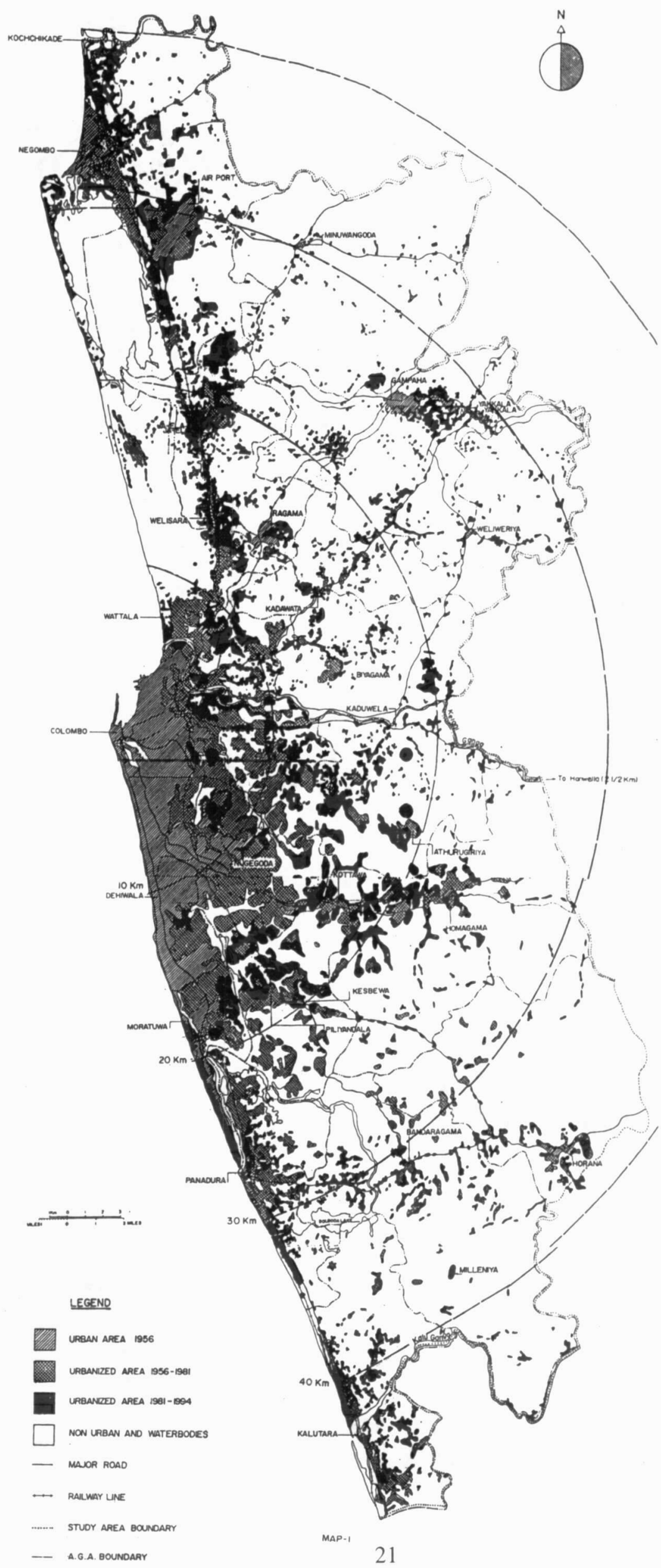




\subsection{Urbanization from 1981 and 1994}

During this period the core area had expanded upto Hokandara in thr east, beyond Kesbewa in the south -east and Pinwatta - in the south. The continuous northward expansion of the core has been constrained by the Muthurajawela marsh. This represents a $47 \%$ expansion of the core area of 1981, yet its share of the total urban area had declined to $56 \%$ (table 1). The area within a $10 \mathrm{~km}$ radius of Colombo is almost completely urban.

In the outer areas, ribbon development was pronounced along Ja -ela - Minuwangoda road, Negombo - Minuwangoda road, Colombo - Kandy road, High Level road and Ppanadura -Horana road. Further there was urban expansion around Gampaha town, around Airport at Katunayake, and around Kalutara town ( map 1).

During the thirteen years upto 1994, the urban had increased to 35,900 ha. Comprising $25 \%$ of the study area. This represented an increase of $68 \%$ over the 1981 figure and an annual increase of 5\% between 1981 and 1994.

The AGA divisions that had the higher percentage of the total urban growth during this period were katana, Kaduwela. Homagama and $\mathrm{Ja}$-ela which together accounted for $38 \%$ of the urban area. This was followed by Kesbewa, Bandaragama and Gampaha which together had $19 \%$ of the total urban growth. More than $50 \%$ of the urban growth, therefore, occurred in these seven AGA divisions ( table 2). .

\subsection{Types of Land Converted to Urban Use}

North and north-east of Colombo, about $70 \%$ of the conversions to urban use were from highlands (coconut lands etc) and the rest from village settlements.

To the east and south- east, conversion to urban use was mostly from village settlements. This explains the densified development in the South-East considering also that about 570 ha of lands in this part are declared flood detention areas. The pattern of conversion was very nearly the same for both periods $1956-1981$ and 1981 -1994 .

Malik Majid was a Senior Scientist at the National
Building Research Organization. This study was
carried out in his capacity as urban planner for the
Colombo Urban Transport Study (1995) carried out by
Halcrow Fox Ltd., UK in association with Engineering
Consultants Ltd. of Colombo, Sri Lanka

Note: An Earlier Version of this paper has been published in 1996, in the Economic Review Sri Lanka 